\title{
Andre Geim: Graphene's buzz has spread
}

The father of graphene talks to Nature about 2D materials, George Osborne, and the business of science.

\section{Elizabeth Gibney}

26 June 2015

MANCHESTER, UK

James King-Holmes/SPL

Andre Geim.

More than 600 physicists have descended on Manchester, UK in the past few days for Graphene Week 2015. The city is billed as the home of graphene: it was here, in 2004, that University of Manchester physicist Andre Geim, with his colleague Konstantin Novoselov, first isolated and explored the properties of a single layer of carbon — work that won them the 2010 Nobel Prize in Physics. At the conference, Geim spoke to Elizabeth Gibney about why the research gold mine of graphene has been exhausted — and how he is working with graphene companies even though he thinks that the mission of a university should not be to push the commercialization of research. The interview has been edited for length and clarity.

\section{Does graphene need a 'killer app' now to justify the money being poured into it?}

What is important about graphene is the new physics it has delivered. Maybe one day, 5 or 10 years from now, it will bring real applications. Should I try to apologize for the lack of killer applications so far? There are many international graphene companies already. So there is nothing to apologize for.

There will always be pressure from taxpayers who want to see an immediate return on investment in terms of something tangible. But take aluminium: it was discovered in the nineteenth century, and for decades no one knew what to do with this material. It was so wonderful, light and strong. And eventually, aircraft came as the killer app. And silicon's story is similar. Whether something like that will happen with graphene and its cousins — other 2D materials — we just don't know.

\section{Many physicists here are excited by 2D materials beyond graphene - are the se a more significant focus now?} I always thought that our 2005 paper [on the electrical properties of a wide range of 2D materials] ${ }^{1}$ was more important than our 2004 Science paper ${ }^{2}$ [on graphene]. It shows that there is a range of 2D materials. Graphene is certainly the most exotic, and is the material that has delivered most scientifically out of all of them. Now, more or less, the gold mine is exhausted, but it remains an important tool in our 2D toolbox.

Graphene continues to deliver wonderful results, such as our work last year on proton transport across graphene ${ }^{3}$, and $2 \mathrm{D}$ water ${ }^{4}$. But the buzz of excitement has spread, not gone - it is more uniformly spread over different materials. Other 2D materials, such as phosphorene and silicene and so on, might be scientifically more exciting. But these require the development of techniques that are still in their infancy or don't exist, to get something of useful quality. So graphene delivers much because of its quantity and stability.

I toured the $£ 61$-million (US\$96-million) National Graphene Institute here [a publicly funded institute designed to help develop and commercialize graphene]. Last month, you were quoted as dismissing it as "money being put into the building industry rather than science".

This was investment in a building, and I welcome this investment. But there should be a balance between new science and new buildings. And I am very concerned because the government can provide only lump sums of money. This is what forces people to put it into bricks and mortar. How to support this and other facilities in the long run, that's a big problem.

How do you feel about the government allocating money directly for the National Graphene Institute, rather than through the UK research councils?

I have always been a vocal and maybe even a vociferous supporter of what is called "responsive mode" [open calls by funders for research applications in any area]. So in this sense I am on the side of those who say the money should be distributed by the research councils. But when we talk about research aimed at particular areas of societal and economic importance, I don't see that the research councils are doing any better jobs than George Osborne himself. Actually, he's less biased in his opinions than many of the research 
councils, and the procedure is quicker.

I realize that I am asking you about matters beyond your research remit. As a Nobel prizewinner, do you often get asked about things that are beyond your scope?

OK, on my excursions into other walks of life - occasionally I am asked, and I have strong views on, economics. Having read dozens of books on economics, I realize that it is not a very precise science. I am on the board of directors of three companies these days, not for any personal profit, but just trying to see how the world operates.

\section{What are those companies doing?}

They are using graphene to gradually improve the quality of products - by $10-20 \%$. It's my investigative project for the moment. The basic knowledge comes from our lab. It is not about killer applications. I don't want to name them, but we are trying to float two companies on the stock market, one by the end of this year. They have several millions of dollars in investment from venture capitalists. This is not what universities should be doing: our social mission is to deliver new knowledge. But in the absence of anyone else, at least in UK society, bridging the gap between academia and industry, we are forced by circumstance to do this.

\section{It's not the job of universities to be commercializing basic research?}

No, it's necessarily not the job of universities to be doing this, but this is a vacuum. We have so many wise people, and rich people, who are ready to invest money and give us advice on how to proceed as academics. The problem is people who want to take all of this and build up a company. It's a huge responsibility and risk. The only people who can be the bridge for this are our PhD students. [At Manchester] we have been trying for many years to make it obligatory for everyone working on graphene and 2D materials to take a course in business. They try to imagine how, on the basis of their knowledge, they could set up their own company after their PhD. Of course, in $90 \%$ of cases it remains role play, but it lowers the psychological barrier. Five doctoral graduates have founded their own companies already. Whether it will work or not, I don't know.

Nature | doi:10.1038/nature.2015.17861

\section{References}

1. Novoselov, K. S. et al. Proc. Natl Acad. Sci. USA 102, 10451-10453 (2005).

2. Novoselov, K. S. et al. Science 306, 666-669 (2004).

3. Hu, S. et al Nature http://dx.doi.org/10.1038/nature14015 (2014)

4. Algara-Siller, G. et al. Nature 519, 443-445 (2015). 